\title{
Ethanol Extract of Caesalpinia decapetala Inhibits Influenza Virus Infection In Vitro and In Vivo
}

\author{
Li Zhang ${ }^{1,2} \mathbb{D}$, Jungang Chen ${ }^{1}$, Chang Ke ${ }^{1}$, Haiwei Zhang ${ }^{1}$, Shoujun Zhang ${ }^{3}$, Wei Tang ${ }^{1}$, \\ Chunlan Liu 1, Ge Liu 1,2, Si Chen 1,2, Ao Hu 1,2, Wenyu Sun 1,2, Yu Xiao 1,2, Minli Liu 1,2 and \\ Xulin Chen $1,2,4, *$ (D) \\ 1 State Key Laboratory of Virology, Wuhan Institute of Virology, Chinese Academy of Sciences, \\ Wuhan 100864, China; zhanglicas000@outlook.com (L.Z.); chenjg@wh.iov.cn (J.C.); \\ xiaobinkechang@hotmail.com (C.K.); hwzhang@wh.iov.cn (H.Z.); tangwei@wh.iov.cn (W.T.); \\ liuchunlan@wh.iov.cn (C.L.); biohazard_1220@hotmail.com (G.L.); chensi880530@outlook.com (S.C.); \\ huaocn@foxmail.com (A.H.); wenyu.sun@hotmail.com (W.S.); xiaoyu.cas@foxmail.com (Y.X.); \\ minli.liu.work@outlook.com (M.L.) \\ 2 University of Chinese Academy of Sciences, Beijing 100049, China \\ 3 Key Laboratory of Plant Germplasm Enhancement and Specialty Agriculture, Wuhan Botanical Garden, \\ Chinese Academy of Sciences, Wuhan 100864, China; zhangshoujun@wbgcas.cn \\ 4 Guangdong Provincial Key Laboratory of Virology, Institute of Medical Microbiology, Jinan University, \\ Guangzhou 510630, China \\ * Correspondence: chenxl@wh.iov.cn; Tel.: +86-27-8719-8772
}

Received: 1 March 2020; Accepted: 15 May 2020; Published: 18 May 2020

\begin{abstract}
Influenza virus infections can lead to viral pneumonia and acute respiratory distress syndrome in severe cases, causing significant morbidity and mortality and posing a great threat to human health. Because of the diversity of influenza virus strains and drug resistance to the current direct antiviral agents, there have been no effective drugs as yet to cure all patients infected by influenza viruses. Natural products from plants contain compounds with diverse structures that have the potential to interact with multiple host and virus factors. In this study, we identified the ethanol extract of Caesalpinia decapetala (Roth) Alston (EEC) as an inhibitor against the replication of a panel of influenza A and B viruses both on human pulmonary epithelial A549 and human monocytic U937 cells. The animal study revealed that EEC administration reduces the weight loss and improves the survival rate of mice infected with lethal influenza virus. Also, EEC treatment attenuated lung injury and reduced virus titer significantly. In conclusion, we showed that EEC has antiviral activity both in vitro and in vivo, suggesting that the plant $C$. decapetala has the potential to be further developed as a resource of new anti-influenza drugs.
\end{abstract}

Keywords: influenza virus; caesalpinia decapetala; antiviral; extract

\section{Introduction}

Despite the availability of vaccines and direct-acting antiviral drugs, influenza causes substantial morbidity and mortality every year [1]. Vaccination is limited to the known epidemic strains and takes a long time for preparation [2,3]. There are many problems with the present anti-influenza drugs [4]. Amantadine and amantadine, inhibitors of the M2 ion channel, have been used for decades [5]. With strong side effects and emergence of widespread drug-resistant strains, they are no longer recommended to treat influenza [6]. Current therapy for influenza includes virus neuraminidase inhibitors and polymerase inhibitors [7]. The neuraminidase (NA) inhibitors: oseltamivir, peramivir, and zanamivir, should be administered within $48 \mathrm{~h}$ of the onset of symptoms [8]. For advanced and severely ill patients, there is no significant improvement in clinical effect [9]. The most recently 
approved drug baloxavir targets virus polymerase [10]. However, according to the clinical results, compared with treatment in adults, baloxavir showed only a weak therapeutic effect in the susceptible population that includes children, adolescents, and the elderly, which cannot shorten the course of the disease [11]. Since influenza causes a huge burden on society every year in most countries in the treatment of seasonal and pandemic flu, there is an urgent need to develop new anti-influenza drugs against a broad spectrum of influenza viruses, including the resistant strains [12].

Plants produce a rich and diverse array of natural products; they have had a long history of medicinal use $[13,14]$. Among them, artemisinin, one of the most famous drugs, was extracted from Artemisia annua and has been used to treat malaria [15]. To explore the potential of plant extracts in the treatment of influenza, we collected 600 species of plants from Shen Long Jia, Hubei province, China. By screening the extract library comprising the ethanol extracts of the 600 plants in a U937 cell model against influenza virus infection [16], we found that the ethanol extract of Caesalpinia decapetala (Roth) Alston (EEC) has antiviral activity against influenza virus infection. Caesalpinia decapetala (Roth) Alston (C. decapetala) is a climbing shrub, belonging to the Caesalpinia genus of the Fabaceae family, which is distributed all over the world [17]. Chemical investigations revealed that EEC contains a variety of components, such as cassane diterpenoid, spathulenol, lupeol, resveratrol, quercetin, stigmasterol, astragalin, and sitosterol $[18,19]$. The extract of $C$. decapetala has been reported to have analgesic, anti-oxidant, anti-tumor, and anti-fertility activities [20,21]. The roots of $C$. decapetala are used as a folk medicine to prevent colds, treat bronchitis, and malaria [20]. However, the extract of $C$. decapetala has never been demonstrated experimentally to have antiviral activity.

In this study, we studied the anti-influenza activity of EEC, both in vitro and in vivo. EEC showed a broad-spectrum inhibitory effect on the replication of all strains of influenza viruses tested on Madin-Darby Canine Kidney (MDCK), A549, and U937 cells. The animal experiments showed that EEC could improve the survival rate of mice infected with lethal influenza virus and decrease the virus titers and pathological damage to the lungs. Our results suggested that EEC has the potential to be a plant-derived drug with further research and development.

\section{Materials and Methods}

\subsection{Cell Lines, Virus Strains}

The Madin-Darby Canine Kidney (MDCK) cells (ATCC CCL-34), human pulmonary epithelial (A549) cells (ATCC CCL-185), and human monocyte cell line U973 (ATCC CRL-1593.2) were all preserved in the laboratory. MDCK was cultured in Dulbecco's modified Eagle's medium, while A549 and U937 cells were cultured in RPMI-1640 medium, both were supplemented with 10\% fetal bovine serum (FBS; Gibco, NY, USA), $100 \mathrm{U} / \mathrm{mL}$ penicillin and $100 \mathrm{U} / \mathrm{mL}$ streptomycin. All these cells were maintained at $37^{\circ} \mathrm{C}$ in a $5 \% \mathrm{CO}_{2}$ incubator.

Influenza virus strains A/Puerto Rico/8/1934 (H1N1), A/Puerto Rico/8/1934 (H1N1, H274Y oseltamivir-resistant), A/human/Hubei/1/2009 (H1N1), A/human/Hubei/3/2005/(H3N2), A/duck/Hubei/216/1983 (H7N8) and B/human/Hubei/1/2007 (IBV) were provided by the virus collection at Wuhan Institute of Virology, Chinese Academy of Sciences, China and amplified from 10-day-old chicken embryos. The virus titers of different influenza strains were determined using $50 \%$ tissue culture infective dose $\left(\mathrm{TCID}_{50}\right)$ assay in MDCK cells.

\subsection{Preparation of Ethanol Extracts of Plants}

The 600 plants were collected from Shen Long Jia, Hubei province, China, followed by extraction with $75 \%$ aqueous ethanol. In the confirmation and efficacy study, C. decapetala was authenticated and collected from the Wuhan Institute of Botany, Chinese Academy of Sciences. Dried leaves and branches of $C$. decapetala were extracted with $75 \%$ aqueous ethanol at room temperature overnight. After filtration, the ethanol extract of $C$. decapetala was stored at $4{ }^{\circ} \mathrm{C}$ for further use. The concentration of the extract was determined by the weight of vacuum freeze-dried extract over its original volume. 


\subsection{Cytotoxicity Assay}

Cells in 96 well cell culture plates were treated with drugs and cultured at $37^{\circ} \mathrm{C}$ for $48 \mathrm{~h}$. The cell viabilities were determined using CellTiter-Glo (Promega, Madison, WI, USA) reagent according to the manufacturer's protocol. The luminescence intensity was determined using a multi-label plate reader (Wallac Envision, PerkinElmer, MA, USA). Three independent experiments were performed in duplicate for the calculation of 50\% cell cytotoxic concentration $\left(\mathrm{CC}_{50}\right)$ using Prism v.6 software.

\subsection{Antiviral Assay}

For the antiviral assay, cells were plated and infected with the influenza virus in the presence or absence of the drug. After incubation at $37^{\circ} \mathrm{C}$ for $48 \mathrm{~h}$, the inhibition of viral replication was measured by the modified neuraminidase activity (NA) assay (Ivachtchenko et al., 2013). The fluorescence intensity was measured with a multi-label plate reader (Wallac Envision, PerkinElmer, MA, USA) and was expressed as the $50 \%$ effective (inhibitory) concentration $\left(\mathrm{EC}_{50}\right)$. For detection of the production of infectious virus virions, the supernatants, harvested $48 \mathrm{~h}$ post-infection (hpi), were titrated through the $\mathrm{TCID}_{50}$ assay, and the virus titers were calculated according to the method of Spearman-Karber [22].

\subsection{Neuraminidase Assay}

The fluorescent substrate, 2'-(4-methylumbelliferyl)-a-D-N-acetylneuraminic acid (MUNANA, Sigma, M8639), for the neuraminidase (NA) of influenza viruses was used to detect the levels of NA. Briefly, the virus-containing culture supernatant was transferred to a black opaque 96 or 384 well plate (PerkinElmer, 6005270 or 6007270) and mixed with $20 \mu \mathrm{mol} / \mathrm{L}$ of MUNANA dissolved in MES solution (33 mmol/L 2-[N-morpholino] ethanesulfonic acid and $4 \mathrm{mmol} / \mathrm{L} \mathrm{CaCl} 2, \mathrm{pH}=6.5)$, followed by incubation at $37^{\circ} \mathrm{C}$ for $1 \mathrm{~h}$. The reaction was terminated by the addition of stop solution $(0.14 \mathrm{~mol} / \mathrm{L}$ $\mathrm{NaOH}$ in $83 \%$ ethanol). Fluorescence intensity was measured at an excitation wavelength of $355 \mathrm{~nm}$ and an emission wavelength of $485 \mathrm{~nm}$ using multi-label plate readers (Envision2103, PerkinElmer, Waltham, MA, USA).

\subsection{Animal Experiment}

BALB/c mice aged 6-8 weeks were purchased from Beijing Vital River Laboratory Animal Technology and raised in the Animal bio-safety level II (ABSL-2) Laboratory of Wuhan Institute of Virology, CAS. All animal experiments were conducted according to the protocol approved by the Animal Care and Use Committee of Wuhan Institute of Virology of the Chinese Academy of Sciences (WIVA08201601). Mice were anesthetized with pentobarbital sodium and then infected with the influenza virus through the nasal cavity. Infected mice were treated by intragastric managed drug once a day for five consecutive days, starting $3 \mathrm{~h}$ after infection. During the experimental period of 18 days, the weight changes and survival rates were recorded. On days 3 and 7 post-infection, the lungs of mice were inflation fixed in 10\% formalin and paraffin-embedded and then stained with hematoxylin and eosin (H\&E). The lung lavage fluids (BALFs) were collected with precooled $0.1 \%$ BSA in PBS and followed by centrifugation at $1500 \mathrm{rpm}$. The virus titers were measured by the TCID $\mathrm{D}_{50}$ method.

\subsection{Statistical Analyses}

The $50 \%$ effective concentrations (EC50s) and 50\% cytotoxic concentrations (CC50s), and selective indices (SIs) in the in vitro study were calculated by non-linear regression using GraphPad Prism 6.0. Data were presented as mean \pm SD for each point. Differences of averages between control and tests samples in the animal experiments were analyzed using Student's $t$ test. $p$-Values less than 0.05 were considered statistically significant. 


\section{Results}

\subsection{EEC Inhibits Influenza Virus Replication on A549 Cells}

To screen for natural products of plants with anti-influenza activity, we made ethanol extracts of about 600 plant species from Shen Nong Jia, Hubei province, China. By screening these plant extracts, we found that the ethanol extract of $C$. decapetala (EEC) inhibits the replication of the influenza virus on A549 cells. As shown in Figure 1A, EEC inhibited the H1N1 influenza virus PR8 strain infection on $\mathrm{A} 549$ cells, with a $\mathrm{CC}_{50}$ and an $\mathrm{EC}_{50}$ of $326.4 \mu \mathrm{g} / \mathrm{mL}$ and $9.8 \mu \mathrm{g} / \mathrm{mL}$, respectively. The inhibition of virion production was also tested, as can be seen in Figure 1B; the results showed that EEC inhibited the production of infectious virions potently and concentration-dependently. At concentrations higher than $43 \mu \mathrm{g} / \mathrm{mL}$, the production of infectious influenza virions was below the detection limit $(10 \mathrm{TCID} 50 / \mathrm{mL})$. The $\mathrm{EC}_{50}$ of EEC is about $14 \mu \mathrm{g} / \mathrm{mL}$. To exclude the possible cytotoxic effect of EEC on virus replication, we used the indirect immunofluorescence assay (IFA) method to measure the cell viability by DAPI staining and to confirm the inhibitory effect by detection of the expression of M2 protein. As shown in Figure 1C, EEC at $43.2 \mu \mathrm{g} / \mathrm{mL}$ and $14.4 \mu \mathrm{g} / \mathrm{mL}$ inhibited the virus replication completely and about $50 \%$, respectively, which is consistent with that measured by virus production. Importantly, the DAPI staining showed that EEC at these concentrations is not cytotoxic to A549 cells. In conclusion, we demonstrated that EEC inhibits influenza virus replication on A549 cells.

A

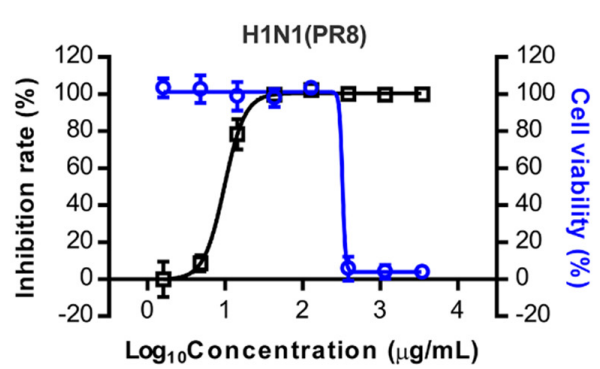

$\mathrm{C}$

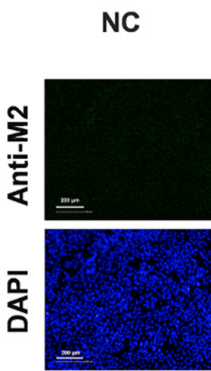

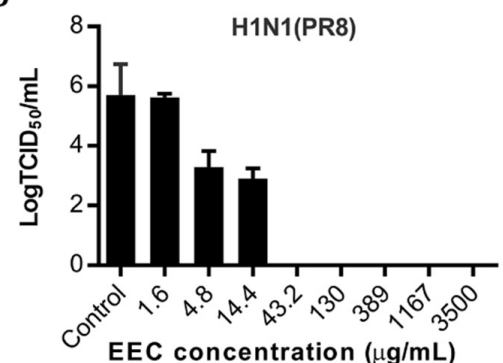

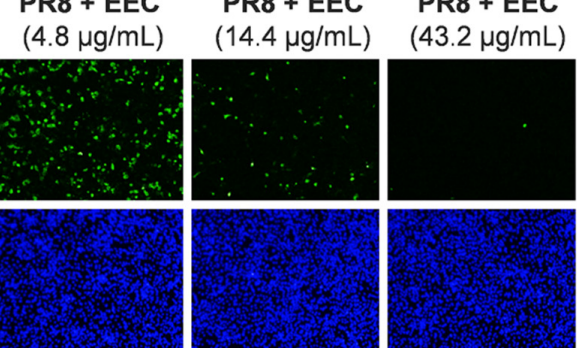

Figure 1. Caesalpinia decapetala (Roth) Alston (EEC) inhibits influenza virus replication in A549 cells. A549 cells were infected with influenza virus A/Puerto Rico/8/1934 (H1N1) at an multiplicity of infection (MOI) of 0.25 in the presence or absence of serially diluted EEC. Cells were then incubated at $37^{\circ} \mathrm{C}$ for $48 \mathrm{~h}$. Cell viabilities were detected by cytotoxicity assay using Cell Titer-Glo reagent (A). The inhibitory effects of EEC on virus replication were determined based on the reduction on NA levels using NA activity assay (A), the production of infectious virions determined by $\mathrm{TCID}_{50}$ Assay (B), and the expression of M2 determined by IFA using the antibody against virus matrix protein 2 (M2) (C).

3.2. EEC Has a Broad Spectrum of Antiviral Activity against a Panel of Influenza Viruses in A549, U937, and MDCK Cells

Human influenza A and B viruses cause annual influenza epidemics, whereas influenza A viruses can also cause sporadic infections or spread worldwide in a pandemic when novel strains emerge in the human population from an animal host [23]. To test the antiviral 
spectrum of EEC against different types and subtypes of influenza viruses, we infected A549 cells with 0.25 MOI of influenza A/Puerto Rico/8/1934, A/Puerto Rico/8/1934 (H274Y), A/human/Hubei/1/2009 (H1N1), A/human/Hubei/3/2005 (H3N2), A/duck/Hubei/216/1983 (H7N8) and B/human/Hubei/1/2007, respectively. The infected cells by each virus were treated with serially diluted EEC. We found that EEC could inhibit all the influenza viruses, including the oseltamivir-resistant H1N1 (H274Y) virus, on A549 cells at a similar efficiency (Figure 2). During infection of humans, the influenza virus can infect multiple cell types, including epithelial cells and monocytes that are important for the pathogenesis of influenza [24]. We next checked the antiviral effect of EEC on epithelial MDCK cells and monocytic U937 cells against both influenza virus A and $B$ viruses. Surprisingly, EEC was found to inhibit all the influenza virus strains both in MDCK cells and U937 cells. Comparing with canine MDCK cells, EEC inhibits more efficiently the replication of influenza viruses in human A549 and U937 cells (Table 1).
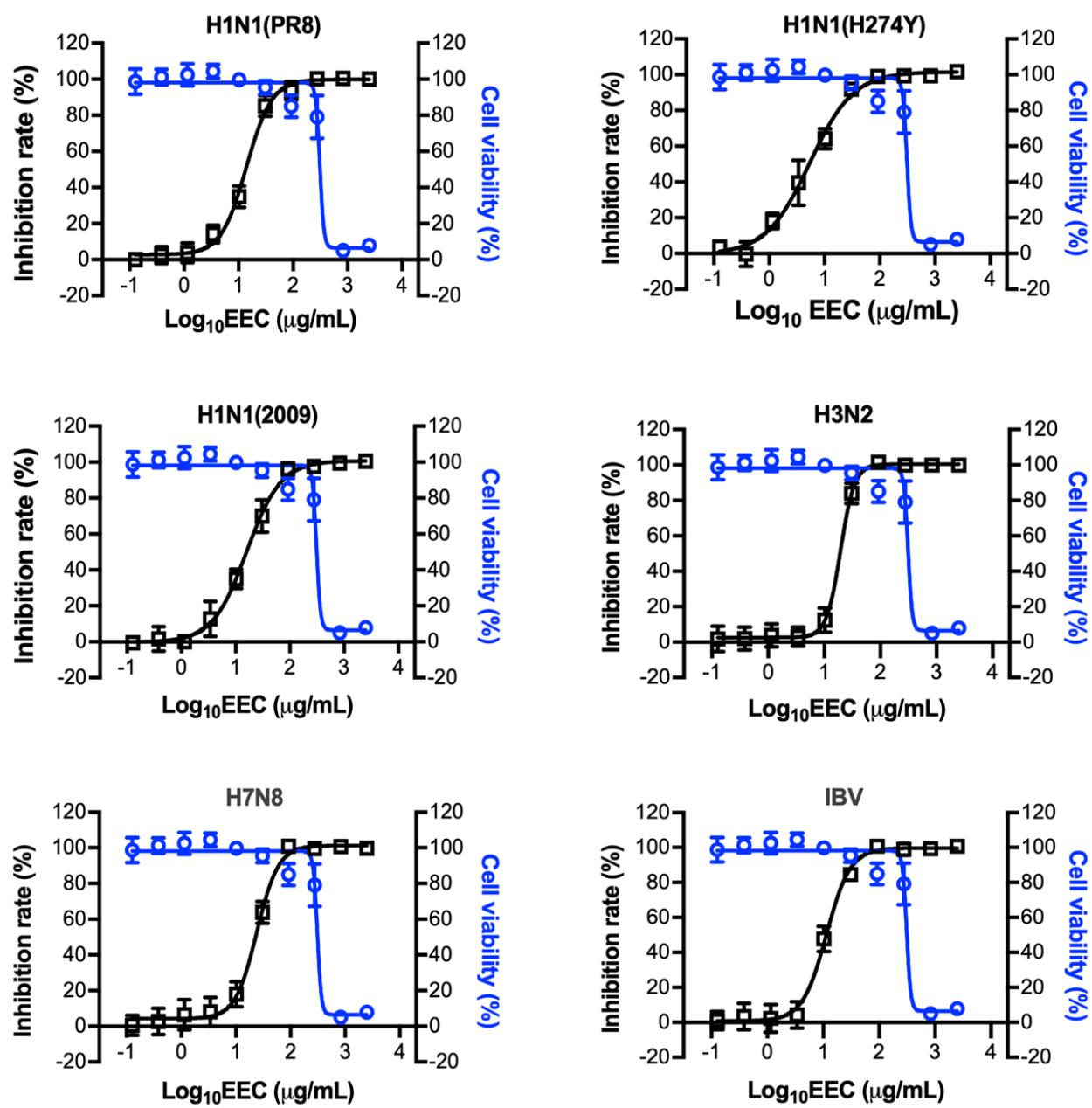

Figure 2. EEC has a broad spectrum of antiviral activities against influenza viruses in A549 cells. A549 cells were infected with influenza viruses A/Puerto Rico/8/1934 (H1N1), A/Puerto Rico/8/1934 (H1N1, H274Y oseltamivir-resistant), A/human/Hubei/1/2009 (H1N1), A/human/Hubei/3/2005 (H3N2), A/duck/Hubei/216/1983 (H7N8) and B/human/Hubei/1/2007 (IBV) at an MOI of 0.25. Serially diluted EEC was added at the same time during the virus infection. The cells were then incubated at $37^{\circ} \mathrm{C}$ for $48 \mathrm{~h}$. Cell viabilities and inhibition rates were determined by Cell Titer-Glo and NA activity assay, respectively. The dose-response curves of EEC against different influenza viruses were made using Prism software (GraphPad Software, San Diego, CA, USA). 
Table 1. Inhibition of 6 different influenza virus strains in A549, Madin-Darby Canine Kidney (MDCK), and U937 cells by Caesalpinia decapetala (Roth) Alston (EEC).

\begin{tabular}{|c|c|c|c|c|c|c|c|c|c|c|c|c|c|}
\hline \multirow{2}{*}{$\begin{array}{l}\text { Virus } \\
\text { Cells }\end{array}$} & \multirow[b]{2}{*}{$\mathrm{CC}_{50}$} & \multicolumn{2}{|c|}{ H1N1(PR8) ${ }^{a}$} & \multicolumn{2}{|c|}{ H1N1(H274Y) ${ }^{b}$} & \multicolumn{2}{|c|}{ H1N1(2009) ${ }^{c}$} & \multicolumn{2}{|c|}{ H3N2 ${ }^{d}$} & \multicolumn{2}{|c|}{$\mathrm{H}_{7 \mathrm{~N} 88^{\mathrm{e}}}$} & \multicolumn{2}{|c|}{ IBV $^{\mathrm{f}}$} \\
\hline & & $\mathrm{EC}_{50}$ & SI & $\mathrm{EC}_{50}$ & SI & $\mathrm{EC}_{50}$ & SI & $\mathrm{EC}_{50}$ & SI & $\mathrm{EC}_{50}$ & SI & $\mathrm{EC}_{50}$ & SI \\
\hline A549 & $311.4 \pm 1.1$ & $14.1 \pm 1.1$ & 22.1 & $5.7 \pm 1.1$ & 55.1 & $16.1 \pm 1.1$ & 19.4 & $18.9 \pm 1.1$ & 16.5 & $23.0 \pm 1.1$ & 13.6 & $11.4 \pm 1.1$ & 27.2 \\
\hline MDCK & $152.7 \pm 1.2$ & $17.7 \pm 1.1$ & 8.6 & $6.7 \pm 1.2$ & 22.7 & $7.2 \pm 1.1$ & 21.2 & $24.6 \pm 1.2$ & 6.2 & $24.3 \pm 1.1$ & 6.3 & $80.2 \pm 1.1$ & 1.9 \\
\hline U937 & $719.9 \pm 1.1$ & $20.5 \pm 1.2$ & 35.1 & $18.7 \pm 1.1$ & 38.5 & $29.2 \pm 1.2$ & 24.7 & $34.5 \pm 1.1$ & 20.9 & $42.0 \pm 1.1$ & 17.1 & $133.5 \pm 1.2$ & 5.4 \\
\hline
\end{tabular}

$\mathrm{CC}_{50}: 50 \%$ cytotoxic concentration $(\mu \mathrm{g} / \mathrm{mL}) ; \mathrm{EC}_{50}: 50 \%$ inhibition concentration $(\mu \mathrm{g} / \mathrm{mL}) ; \mathrm{SI}$ (Selective Index): the ratio of $\mathrm{CC}_{50} / \mathrm{IC}_{50} \cdot{ }^{\text {a }} \mathrm{A} / \mathrm{PuertoRico} / 8 / 1934$ (H1N1); ${ }^{\mathrm{b}} \mathrm{A} / \mathrm{PuertoRico} / 8 / 1934$ (H1N1, H274Y, oseltamivir resistant); ${ }^{\mathrm{c}}$ A/Human/Hubei/1/2009(H1N1); ${ }^{\mathrm{d}}$ A/human/Hubei/3/2005(H3N2);. $.^{\mathrm{e}} \mathrm{A} /$ Duck/Hubei/216/1983(H7N8); ${ }^{\mathrm{f}}$ B/human/Hubei/1/2007. 


\subsection{Determination of the Stage Affected by EEC in the Influenza Virus Life Cycle}

To determine the stage of the influenza virus life cycle inhibited by EEC, a time-of-addition assay was conducted. MDCK cells were infected with $0.1 \mathrm{MOI}$ of influenza virus at $4{ }^{\circ} \mathrm{C}$ for $1 \mathrm{~h}$, followed by cell culture at $37^{\circ} \mathrm{C}$ for $12 \mathrm{~h}$. During the cell culture, three $\mathrm{EC}_{50}$ of ribavirin, oseltamivir, and EEC were added respectively at different time points and maintained for $12 \mathrm{~h}$. The supernatants were collected, and the virus yields were determined by the NA activity assay. As shown in Figure 3A, similar to oseltamivir, EEC inhibited the virus replication completely when added at all time points until $8 \mathrm{hpi}$, indicating that EEC may inhibit the very late stage of the influenza virus life cycle, which includes mainly the release of virions that is related to the function of virus neuraminidase. To determine whether EEC inhibits the virus neuraminidase activity, an in vitro neuraminidase inhibition assay was conducted. As shown in Figure 3B, similar to oseltamivir, EEC inhibited the neuraminidase activity concentration-dependently. Taken together, our results show that EEC inhibits the late stage of the influenza virus life cycle. Since the virus neuraminidase activity is required for the release of virions, we speculate that EEC may inhibit the release of influenza viruses.

A

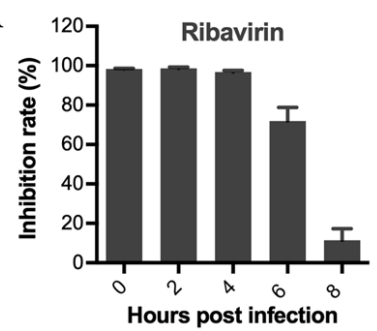

$\mathrm{B}$

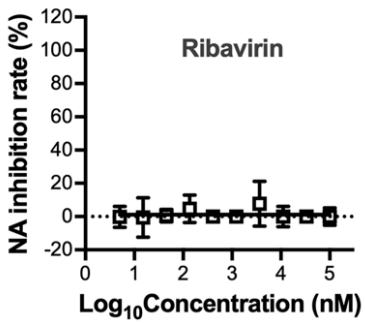

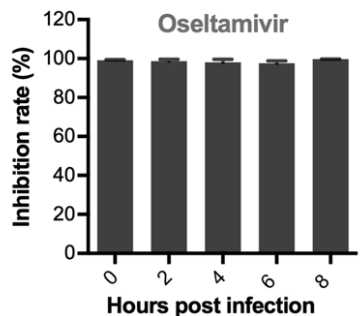

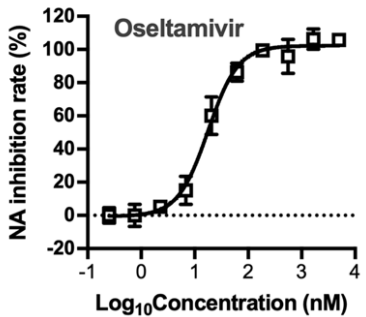

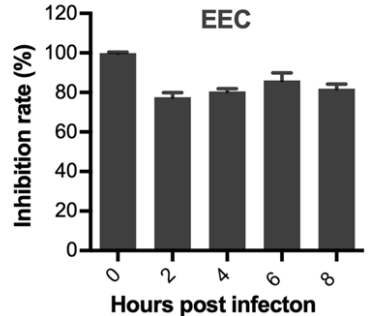

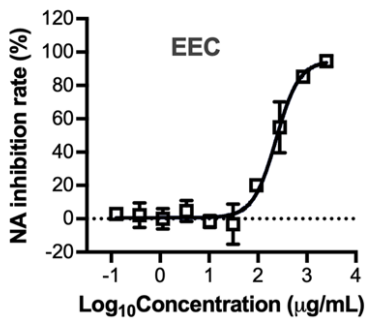

Figure 3. EEC affects the late stage of the influenza virus life cycle by inhibiting neuraminidase activity. The stages of the influenza virus life cycle affected by EEC were determined by time of addition assay and neuraminidase inhibition assay, respectively. (A) In the time of addition assay, pre-cooled MDCK cells were infected with PR8 virus at an MOI of 0.1 at $4{ }^{\circ} \mathrm{C}$ for $1 \mathrm{~h}$. Three $\mathrm{IC}_{50}$ of ribavirin, oseltamivir, and EEC were added in each group at different time points during virus replication on MDCK cells. The supernatants were collected at $12 \mathrm{hpi}$, and the viral yield was determined by the NA activity assay. (B) In the neuraminidase inhibition assay, $95 \mu \mathrm{L}$ of H1N1 PR8 virus solution of $10^{5} \mathrm{TCID}_{50} / \mathrm{mL}$ was mixed with $5 \mu \mathrm{L}$ of serially diluted EEC, ribavirin or oseltamivir, respectively. Each reaction was conducted at $37^{\circ} \mathrm{C}$ for $1 \mathrm{~h}$ in the presence of $20 \mu \mathrm{M}$ MUNANA, the fluorescence intensity was determined using the EnSpire multi-label plate reader (PerkinElmer, MA, USA).

\subsection{EEC Protects Mice from Lethal Influenza Virus Infection}

To further study the therapeutic effect of EEC in vivo, BALB/c mice weighing about $18 \mathrm{~g}$ were infected with four $\mathrm{LD}_{50}$ of H1N1 PR8 virus by the method of intranasal. After $3 \mathrm{~h}$ of infection, each group of mice $(n=10)$ was treated with 60,30 , and $15 \mathrm{mg} / \mathrm{kg} / \mathrm{d}$ of EEC or placebo solution. The mice of the placebo group began to die on day 7 , and all died on day 10 after infection. Compared with the placebo group, the mice treated with $60 \mathrm{mg} / \mathrm{kg} / \mathrm{d}$ of EEC lost weight relatively slow and began to gain weight significantly after day 10 , with a survival rate of $40 \%$ (Figure $4 \mathrm{~A}, \mathrm{~B}$ ). While the mice treated with 30 and $10 \mathrm{mg} / \mathrm{kg} / \mathrm{d}$ of EEC had $30 \%$ and $10 \%$ of survival rate, respectively (Figure $4 \mathrm{~A}, \mathrm{C}, \mathrm{D}$ ). Whereas treatment with the reference drug oseltamivir at $20 \mathrm{mg} / \mathrm{kg} / \mathrm{d}$ protected $80 \%$ of mice from death 
caused by the same lethal dose of PR8 virus infection. These observations suggest that EEC protects mice from lethal influenza virus infection.

A

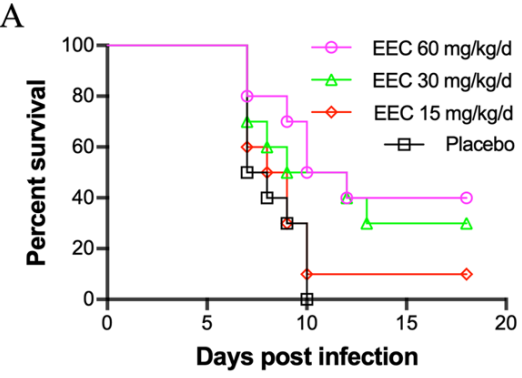

$\mathrm{C}$

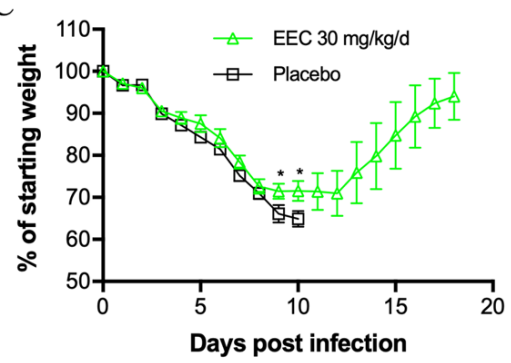

$\mathrm{E}$

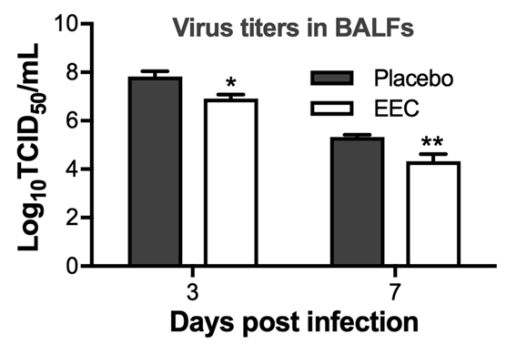

G

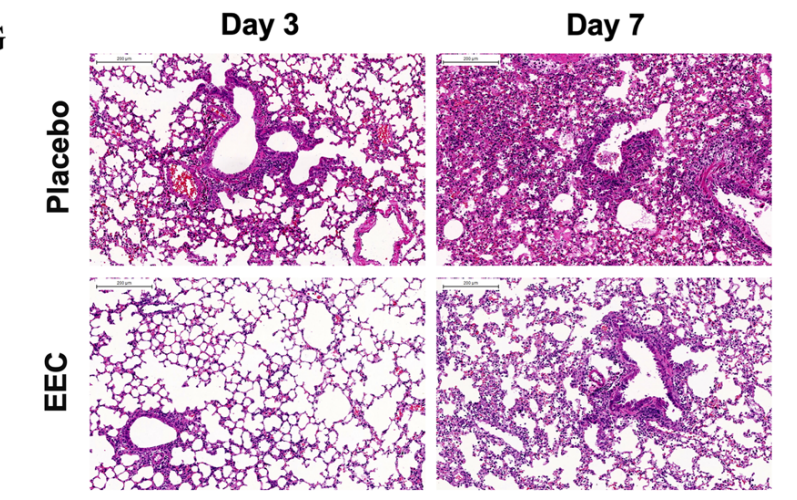

Day 7
B

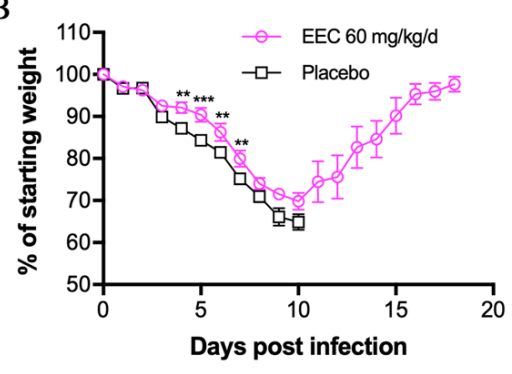

$\mathrm{D}$

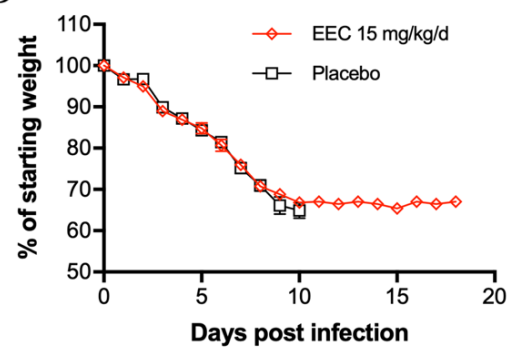

F

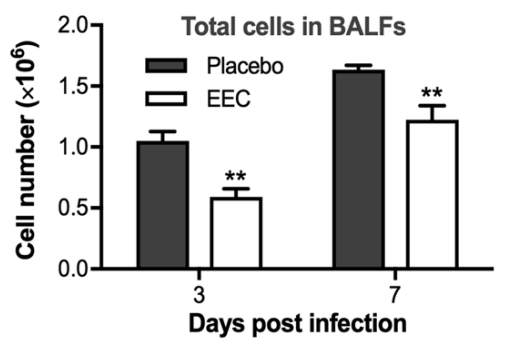

Figure 4. EEC protects mice from lethal influenza virus infection. Six-week-old female BALB/c mice weighing 16-18g were infected with 4 LD 50 of H1N1 PR8 virus intranasally. Three hours after infection, four groups of mice (10 mice in each group) were treated intraperitoneally with $60,30,15 \mathrm{mg} / \mathrm{kg} / \mathrm{d}$ of EEC or placebo solution respectively for five consecutive days. Survival rate (A) and body weight loss (B-D) were monitored daily until day 18 post-infection. Lung lavage fluids (BALFs) from the infected mice treated with $60 \mathrm{mg} / \mathrm{kg} / \mathrm{d}$ of EEC were collected on days 3 and 7 post-infection to monitor virus titers (E), and total cell counts (F) (mean \pm SEM). The data are representative of three independent experiments. ( $n=3$ per group at each time point). ${ }^{*} p<0.05 ;{ }^{* *} p<0.01 ; * * * p<0.001$. Sections from lungs of PR8-infected BALB/c mice treated with $60 \mathrm{mg} / \mathrm{kg} / \mathrm{d}$ of EEC or placebo solution at day 3 and 7 post-infection were H\&E-stained (scale bar $200 \mu \mathrm{m})(\mathbf{G})$. 


\subsection{EEC Reduces Virus Titer and Pathogenic Damage in the Lung Mediated by Influenza Virus Infection}

Even though the selective indexes of EEC in the inhibitory effects against influenza virus A and B strains in human A549 and U937 cells range from 5 to 52 (Table 1), EEC does protect mice from lethal influenza virus infection. To confirm whether EEC inhibits virus replication in vivo, we next checked the virus titers in the BALFs of the infected mice treated with EEC. As shown in Figure 4E, at day 3 and 7 post-infection, the virus titers in the BALFs of mice treated with $60 \mathrm{mg} / \mathrm{kg} / \mathrm{d}$ of EEC decreased significantly (about 10 times) compared with that of the placebo group.

When mice are infected with the influenza virus, a large number of inflammatory cells are often infiltrated in the lung tissue, accompanied by enhanced inflammatory injuries in the lung $[25,26]$. To examine the total cell infiltration and pathological changes in the lungs of mice infected by lethal influenza and treated or untreated with EEC, the total cell counting in the BALFs and H\&E staining of the lung tissue of mice were conducted. As shown in Figure $4 \mathrm{~F}$, the total number of cells at day 3 and 7 in BALFs of mice treated with $60 \mathrm{mg} / \mathrm{kg} / \mathrm{d}$ of EEC decreased by $40 \%$ and 25\%, respectively. A further pathological examination by H\&E staining revealed that the pathogenic damage in the lungs treated with EEC improved significantly at day 3 and 7 post-infection (Figure 4G). We speculate that the reduction in infiltrated cells and pathological damage in the lung may be a result of the decrease in virus titer mediated by the antiviral effect of EEC.

\section{Discussion/Conclusions}

Seasonal influenza is an acute respiratory infection caused by influenza viruses that circulate the world [27]. Influenza A and B viruses cause seasonal epidemics of disease. Currently circulating in humans are subtype $\mathrm{A}(\mathrm{H} 1 \mathrm{~N} 1)$ and $\mathrm{A}(\mathrm{H} 3 \mathrm{~N} 2)$ influenza viruses [28]. Influenza viruses circulating in animals, e.g., birds, pose threats to human health in that they can develop the ability to infect humans and cause illness [29]. In patients with influenza pneumonia, multiple cell types, including epithelial cells, alveolar cells, and monocytes, are infected by the influenza virus and contribute to direct cytopathogenic and inflammatory damage to the lung [30,31]. In our in vitro study, in addition to the commonly used MDCK cells, we tested the antiviral effect of EEC against a panel of influenza viruses on the epithelial A549 cells and monocytic U937 cells. However, the efficacy of EEC is not as good as oseltamivir (data not shown), but comparable to that of ribavirin (Figure S1).

In addition to human influenza A viruses $\mathrm{H} 1 \mathrm{~N} 1$ and $\mathrm{H} 3 \mathrm{~N} 2$, human influenza B virus strains, the 2009 (H1N1) pandemic strain, oseltamivir-resistant strain H1N1 (H274Y), and a bird flu H7N8 were also tested. We did not measure the infectivity using $\mathrm{TCID}_{50}$ assay. Instead, we tested the NA activity on the supernatants of the cell culture since we found that the $\mathrm{TCID}_{50} \mathrm{~s}$ are correlated pretty well with the NA activities from the same virus-containing supernatants using a fluorescent substrate (Figure S2). Our results showed that EEC has a broad-spectrum of anti-influenza activity in multiple cell types, suggesting EEC has the potential to treat influenza.

Next, the therapeutic effect of EEC was tested on a mouse influenza model. Our results demonstrated that EEC protected mice from lethal influenza infection by increasing the survival rate that is associated with decreased virus titer, cell infiltration, and inflammatory damage to the lung. We assume that the antiviral activity of EEC contributes mainly to the therapeutic effect. Furthermore, a preliminary mechanism study revealed that EEC inhibits the neuraminidase activity and interferes with the late stage of the virus life cycle. It is worth noting that when extracted with pure $\mathrm{H}_{2} \mathrm{O}$ or ethanol, the extract of $C$. decapetala exhibits different antiviral activity and cytotoxicity from that extracted with $75 \%$ aqueous ethanol (data not shown). This observation suggests that the extraction methods can influence the efficacy of EEC on its antiviral activity and cytotoxicity. Further optimization of the extraction method for anti-influenza drug development is needed.

Herb medicine has a long history of being used to treat the flu. Many studies have identified bioactive components or compounds in plant extracts that may be useful for treating influenza. A variety of polyphenols, flavonoids, alkaloids, essential oils, and aromatic compounds isolated from medicinal plants and plant extracts have been extensively studied and tested for anti-influenza 
activity [32]. However, most of the efficacy studies were conducted in vitro; only a few extracts or compounds were demonstrated to be effective in vivo. Among the in vivo studies, Bing et al. reported that the total alkaloid extract from Commelina communis showed antiviral activity against influenza virus H1N1 in vivo [33]. Utsunomiya et al. found that glycyrrhizin, an active component of licorice roots, could protect mice exposed to a lethal H2N2 virus through the stimulation of IFN-gamma production by $\mathrm{T}$ cells. Glycyrrhizin, by itself, does not inhibit influenza virus replication [34]. Compared with these reported herb medicines, EEC showed similar efficacy to the total alkaloid extract from Commelina communis. However, it is less potent than glycyrrhizin in increasing survival rate, though they both can lower the virus titer in the lung of mice for about one log value. When compared to the clinical drug oseltamivir, EEC showed less potency both in increasing survival rate and in lowering virus titer.

EEC, at its current formula, may be not ideal as an anti-influenza drug. However, the plant C. decapetala (Roth) Alston can serve as a resource of natural products to be developed as a plant-derived drug against influenza. Further research is in progress to isolate and elucidate the bioactive components or compounds responsible for the antiviral activity of this plant and to determine their mechanisms of action. To the best of our knowledge, this is the first report of the antiviral activity of $C$. decapetala (Roth) Alston. Our findings suggest that the ethnobotanical use of plant drugs may provide benefits in the treatment of influenza, warranting further investigation.

Supplementary Materials: Supplementary materials can be found at http://www.mdpi.com/1999-4915/12/5/557/s1. Figure S1: Antiviral effects of ribavirin against influenza virus PR 8 were determined in A 549 U 937 and MDCK cells; Figure S2: Correlation analysis of the TCID 50 and neuraminidase (NA) activity of influenza virus solutions produced in cell culture.

Author Contributions: X.C. and L.Z. conceived and designed the experiments. L.Z. practically performed the experiments. W.T. and C.L. were responsible for reagents. J.C., C.K., H.Z., S.Z., L.Z., and X.C. were responsible for extract preparation and storage. G.L., S.C., and M.L. contributed methodology. L.Z. and A.H. performed statistical analysis of the data. W.S. and Y.X. contributed analysis tools. L.Z. and X.C. wrote the paper. All authors have read and agreed to the published version of the manuscript.

Funding: This work was supported by the Wuhan Applied Basic Research Frontier Program 2019020701011448 (to X.C.).

Acknowledgments: We thank Ding Gao and Juan Min (Center for instrumental analysis and metrology, Wuhan Institute of Virology, CAS) and Xuefang An (Center for animal experiments) for technical support.

Conflicts of Interest: The authors declare no conflict of interest. The funders had no role in the design of the study; in the collection, analyses, or interpretation of data; in the writing of the manuscript, or in the decision to publish the results.

\section{References}

1. Iuliano, A.D.; Roguski, K.M.; Chang, H.H.; Muscatello, D.J.; Palekar, R.; Tempia, S.; Mustaquim, D. Estimates of global seasonal influenza-associated respiratory mortality: A modelling study. Lancet 2018, 391, 1285-1300. [CrossRef]

2. Krammer, F. The human antibody response to influenza A virus infection and vaccination. Nat. Rev. Immunol. 2019, 19, 383-397. [CrossRef] [PubMed]

3. Yamayoshi, S.; Kawaoka, Y. Current and future influenza vaccines. Nat. Med. 2019, 25, 212-220. [CrossRef] [PubMed]

4. Darwish, I.; Mubareka, S.; Liles, W.C. Immunomodulatory therapy for severe influenza. Expert Rev Anti-Infect. Ther. 2011, 9, 807-822. [CrossRef]

5. Dunning, J.; Baillie, J.K.; Cao, B.; Hayden, F.G. Antiviral combinations for severe influenza. Lancet Infect. Dis. 2014, 14, 1259-1270. [CrossRef]

6. Jefferson, T.; Demicheli, V.; Rivetti, D.; Jones, M.; Di Pietrantonj, C.; Rivetti, A. Antivirals for influenza in healthy adults: Systematic review. Lancet 2006, 367, 303-313. [CrossRef]

7. Van Dongen, M.J.P.; Kadam, R.U.; Juraszek, J.; Lawson, E.; Brandenburg, B.; Schmitz, F.; Wilson, I.A. A small-molecule fusion inhibitor of influenza virus is orally active in mice. Science 2019, 363, pii:eaar6221. [CrossRef] 
8. Naesens, L.; Stevaert, A.; Vanderlinden, E. Antiviral therapies on the horizon for influenza. Curr. Opin. Pharmacol. 2016, 30, 106-115. [CrossRef]

9. Paules, C.; Subbarao, K. Influenza. Lancet 2017, 390, 697-708. [CrossRef]

10. Shinya, O.; Valentina, S.; Takashi, H.; Takeshi, N.; Hiroto, Y.; Makoto, K.; Keiko, K.; Takeki, U.; Takao, S.; Akira, N.; et al. Characterization of influenza virus variants induced by treatment with the endonuclease inhibitor Baloxavir Marboxil. Sci. Rep. 2018, 8, 9633.

11. Hayden, F.G.; Sugaya, N.; Hirotsu, N.; Lee, N.; de Jong, M.D.; Hurt, A.C.; Ishida, T.; Sekino, H.; Yamada, K.; Portsmouth, S.; et al. Baloxavir marboxil for Uncomplicated Influenza in Adults and Adolescents. N. Engl. J. Med. 2018, 379, 913-923. [CrossRef] [PubMed]

12. Hurt, A.C. The epidemiology and spread of drug resistant human influenza viruses. Curr. Opin. Virol. 2014, 8, 22-29. [CrossRef] [PubMed]

13. Han, X.; Zhang, D.-K.; Guo, Y.-M.; Feng, W.-W.; Dong, Q.; Zhang, C.-E.; Zhou, Y.-F.; Liu, Y.; Wang, J.-B.; Zhao, Y.-L.; et al. Screening and evaluation of commonly-used anti-influenza Chinese herbal medicines based on anti-neuraminidase activity. Chin. J. Nat. Med. 2016, 14, 794-800. [CrossRef]

14. Zu, M.; Yang, F.; Zhou, W.; Liu, A.; Du, G.; Zheng, L. In vitro anti-influenza virus and anti-inflammatory activities of theaflavin derivatives. Antivir. Res. 2012, 94, 217-224. [CrossRef] [PubMed]

15. Klayman, D. Qinghaosu (artemisinin): An antimalarial drug from China. Science 1985, 228, 1049-1055. [CrossRef] [PubMed]

16. Liu, G.; Chen, S.; Hu, A.; Zhang, L.; Sun, W.; Chen, J.; Tang, W.; Zhang, H.; Liu, C.; Ke, C.; et al. The Establishment and Validation of the Human U937 Cell Line as a Cellular Model to Screen Immunomodulatory Agents Regulating Cytokine Release Induced by Influenza Virus Infection. Virol. Sin. 2019, 34, 648-661. [CrossRef]

17. Kamikawa, S.; Oshimo, S.; Ohta, E.; Nehira, T.; Ômura, H.; Ohta, S. Cassane diterpenoids from the roots of Caesalpinia decapetala var. japonica and structure revision of caesaljapin. Phytochemistry. 2016, 121, 50-57. [CrossRef]

18. Li, M.; Zhang, C.; Chong, L. Studies on chemical constituents of Caesalpinia decapetala (Roth) Alston. Zhong Yao Cai = Zhongyaocai = J. Chin. Med. Mater. 2002, 25, 794-795.

19. Wei, X.-H.; Yang, S.-J.; Liang, N.; Hu, D.-Y.; Jin, L.-H.; Xue, W.; Yang, S. Chemical Constituents of Caesalpinia decapetala (Roth) Alston. Molecules 2013, 18, 1325-1336. [CrossRef]

20. Gallego, M.; Gordon, M.; Segovia, F.; Almajano, M. Caesalpinia decapetala Extracts as Inhibitors of Lipid Oxidation in Beef Patties. Molecules 2015, 20, 13913-13926. [CrossRef]

21. Pawar, C.R.; Surana, S.J. Antioxidant Properties of the Methanol Extract of the Wood and Pericarp of Caesalpinia decapetala. J. Young Pharm. 2010, 2, 45-49. [CrossRef] [PubMed]

22. Kärber, G. Beitrag zur kollektiven Behandlung pharmakologischer Reihenversuche. Archiv der experimentiellen. Pathol. Pharmakol. 1931, 162, 480-483.

23. Cox, N.; Subbarao, K. Global epidemiology of influenza: past and present. Ann. Rev. Med. 2000, 51, 407-421. [CrossRef] [PubMed]

24. Kapoor, S.; Dhama, K. Pathogenesis and Pathogenicity of Influenza Viruses. In Insight into Influenza Viruses of Animals and Humans; Springer: Cham, Switzerland, 2014.

25. Iwasaki, A.; Pillai, P. Innate immunity to influenza virus infection. Nat. Rev. Immunol. 2014, 14, $315-328$. [CrossRef]

26. Short, K.; Kroeze, E.; Fouchier, R.; Kuiken, T. Pathogenesis of influenza-induced acute respiratory distress syndrome. Lancet Infect. Dis. 2013, 14, 57-69. [CrossRef]

27. Krammer, F.; Smith, G.; Fouchier, R.; Peiris, J.S.; Kedzierska, K.; Doherty, P.C.; Palese, P.; Shaw, M.L.; Treanor, J.; Webster, R.G.; et al. Influenza. Nat. Rev. Dis. Primers 2018, 4, 3. [CrossRef]

28. Han, A.; Giurgea, L.; Cervantes-Medina, A.; Edwards, K.; Rosas, L.; Czajkowski, L.; Buas, H.A.; Athota, R.; Reed, S.; Taubenberger, J.; et al. Sequential Influenza A H1N1 and Influenza A H3N2 Challenge Infections in Healthy Volunteers. Open Forum Infect. Dis. 2019, 6, S969. [CrossRef]

29. Zhang, X.; Sun, H.; Cunningham, F.; Li, L.; Hanson-Dorr, K.; Hopken, M.W.; Cooley, J.; Long, L.-P.; Baroch, J.A.; $\mathrm{Li}, \mathrm{T}$; et al. Tissue tropisms opt for transmissible reassortants during avian and swine influenza A virus co-infection in swine. PLoS Pathog. 2018, 14, e1007417. [CrossRef]

30. Liu, Q.; Zhou, Y.-H.; Yang, Z.-Q. The cytokine storm of severe influenza and development of immunomodulatory therapy. Cell. Mol. Immunol. 2015, 13, 3-10. [CrossRef] 
31. Peiris, J.S.; Hui, K.; Yen, H.-L. Host response to influenza virus: Protection versus immunopathology. Curr. Opin. Immunol. 2010, 22, 475-481. [CrossRef]

32. Chon, H. Chapter 11-Medicinal Herbs and Plant Extracts for Influenza: Bioactivity, Mechanism of Anti-influenza Effects, and Modulation of Immune Responses. Stud. Nat. Prod. Chem. 2012, 38, 305-323.

33. Bing, F.H.; Liu, J.; Li, Z.; Zhang, G.B.; Liao, Y.F.; Li, J.; Dong, C.Y. Anti-influenza-virus Activity of Total Alkaloids from Commelina communis. L. Arch. Virol. 2009, 154, 1837-1840. [CrossRef] [PubMed]

34. Utsunomiya, T.; Kobayashi, M.; Pollard, R.B.; Suzuki, F. Glycyrrhizin, an Active Component of Licorice Roots, Reduces Morbidity and Mortality of Mice Infected With Lethal Doses of Influenza Virus. Antimicrob Agents Chemother 1997, 41, 551-556. [CrossRef] [PubMed]

(C) 2020 by the authors. Licensee MDPI, Basel, Switzerland. This article is an open access article distributed under the terms and conditions of the Creative Commons Attribution (CC BY) license (http://creativecommons.org/licenses/by/4.0/). 